\title{
THE PSYCHO-GALVANIC REFLEX: A PHARMACOLOGICAL STUDY OF THE PERIPHERAL MECHANISM
}

\author{
M. H. LADER AND J. D. MONTAGU
}

From the Department of Pharmacology, University College, London

The psycho-galvanic reflex is a decrease in the electrical resistance of the skin which occurs in response to a wide variety of stimuli. The physiological basis of this autonomic measure, known also as the galvanic skin response or electro-dermal response, has not yet been fully elucidated.

There are two principal theories accounting for the phenomenon. The vascular theory, proposed by Féré (1888) and elaborated by McDowall (1933), maintains that it is caused by a change in tone of the blood vessels of the skin. The second theory, with many more adherents, was advanced by Tarchanoff (1890), who suggested that it was due to changes in the secretory activity of the sweat glands. This was later modified to changes in the pre-secretory activity of the sweat glands, and the studies of Darrow (1927) lent strong support to this view.

Investigators who have tested the secretory theory have sought to do so by attempting to prevent secretory activity by means of atropine. The results, however, have been conflicting, as exemplified by two of the more recent investigations in this field. In the first of these Carmichael, Honeyman, Kolb, and Stewart (1941) found that local atropinization by iontophoresis did not abolish the psychogalvanic reflex. On the other hand, Montagu (1958), using the same technique and dosage, obtained opposite results.

The vascular theory has been tested by determining the effect on the psycho-galvanic reflex of exsanguinating an extremity with an Esmarch's bandage. By this means workers have succeeded in producing either a marked reduction (Carmichael et al., 1941) or complete abolition (Goadby and Goadby, 1949) of the psycho-galvanic reflex. The recent introduction of post-ganglionic, adrenergic, neurone-blocking agents such as bretylium ( $\mathrm{N}$-o-bromobenzyl- $\mathrm{N}$ ethyl-NN-dimethyl-ammonium) seemed to the authors to afford a more convenient means of modifying vasomotor activity.

The object of this paper is to report two series of experiments in which the skin resistance and the pulse volume were recorded simultaneously from the same finger. In one series, atropine was admin- istered locally by iontophoresis in order to paralyse the cholinergically innervated sweat glands; in the other, bretylium was used in a similar fashion to paralyse the adrenergic nerve endings governing vasomotor tone.

\section{METHODS}

SUBJECTS The subjects were five male and three female volunteers, who were staff or students of the College. Two of the subjects were studied intensively, and a total of 30 experiments was performed.

EXPERIMENTAL CONDITIONS The investigations took place in a quiet room, the temperature of which was thermostatically controlled at 22 to $23^{\circ} \mathrm{C}$. The subject lay on an examination couch which was separated from the recording equipment by a screen.

SKIN RESISTANCE The subject was connected in series with 15 megohms to a stabilized D.C. source of 150 volts. The current through the subject was adjusted to equal $10 \mu \mathrm{A}$. when the subject's resistance was 100,000 ohms, and it remained constant to within narrow limits over the entire recorded range of resistances. The voltage developed across the subject was balanced in steps of 0.5 volt to the nearest 0.5 volt, each step being equivalent to a resistance of 50,000 ohms. The residual unbalanced voltage was attenuated and was then amplified by a Grass D.C. amplifier. There were five sensitivity ranges giving full scale deflection for resistance changes of $\pm 500,250,100$, 50 , and 25 kilohms from the reference level. The input resistance of the instrument was 20 megohms. Two similar instruments were used.

ELECTRODES These consisted of flat lead discs which were sanded bright before each experiment. The earthed 'inactive' electrode was $2.5 \mathrm{~cm}$. in diameter; the 'active' electrodes were $1 \mathrm{~cm}$. in diameter. The earthed electrode was secured to the dorsum of the right forearm by an adjustable cloth strap. To minimize the electrical resistance and activity of this area the skin was first rubbed briskly with an emery board until a moderate erythema was elicited. Cambridge electrode jelly was then rubbed in well. The active electrode was attached by adhesive tape to the palmar surface of the tip of a finger of the right hand. Surface grease was first removed by wiping the area lightly with cottonwool dipped in trichlorethylene. No other preparation was made and no contact 
medium was used. Lead electrodes in contact with sodium chloride are known to be subject to polarization, which can cause an increase in apparent resistance of the order of 20,000 ohms during one hour when a current of $50 \mu \mathrm{A}$. is passed (Lykken, 1959). Such changes would not, however, affect the validity of the present results. Moreover, the current used in these experiments was one-fifth of that used in Lykken's tests.

PULSE VOLUME The right hand was placed in a comfortable position on a table, the height of which was adjusted so that the hand was at the same level as the right atrium. A metal oncometer cuff was chosen to fit the finger comfortably but not sufficiently tightly to interfere with venous drainage. After the skin resistance electrode had been applied, the finger was inserted into the cuff as far as the distal interphalangeal crease, and silicone stopcock grease was smeared round the rim to make an airtight seal. The cuff had two outlets. The lead to the electrode was passed through one and the gap was plugged with silicone grease. To the other outlet was connected a polythene tube of low distensibility which led via a twoway tap to a Grass P.T.5 volume transducer. By means of the tap the system could be opened to the atmosphere in order to equalize the pressures on either side of the transducer diaphragm. The transducer was connected to a Grass model 5P1 preamplifier which had been slightly modified. The time constant was $0 \cdot 1$ second. The tracing consisted of a series of upward deflections of the pen, which represented the transient increases in finger volume resulting from the pulse beats. Two similar transducers and amplifiers were used.

RECORDING INSTRUMENT The recorder consisted of a Grass model 5 polygraph fitted with three D.C. amplifiers and ink-writing oscillographs. A chart speed of $0.6 \mathrm{~mm}$./ second was used.

QUANTIFICATION OF RESUlts Psycho-galvanic reflexes were measured as changes in conductance, i.e., the difference between the maximum conductance attained during the 10 seconds after the stimulus and the immediate pre-stimulus level. Pulse volume reactivity was assessed by measuring the mean amplitude of the six beats immediately preceding the stimulus and subtracting the amplitude of the smallest beat in the 10-second period following the stimulus. This decrease in pulse volume was expressed as a percentage of the pre-stimulus level.

STIMULI Four types of stimuli were applied: (1) The flash of a 100-watt light bulb; (2) a variety of auditory stimuli, e.g., a shot from a cap gun and an acoustic feedback whistle; (3) the subject was instructed to take a deep breath; and (4) a cold pressor test in which the left hand was immersed in ice-cold water for 10 seconds (bretylium experiments only). In addition to the 'induced' responses, spontaneous fluctuations of similar appearance were commonly observed in both measures, presumably occurring in response to unidentified stimuli. These responses were more pronounced in the pulse volume tracings, the pulse volume amplitude frequently decreasing to quite low levels. During each experiment, therefore, the stimuli were only applied when the pulse volume was deemed to be of sufficient amplitude to be capable of a measurable response. The various stimuli were applied in an irregular sequence in order to minimize the effects of habituation and anticipation.

DRUGS The drugs were administered locally by iontophoresis, as follows:-

Atropine sulphate The distal half of the finger was placed in a solution of $3 \%$ atropine sulphate in distilled water contained in a small beaker. A stout platinum wire dipping into this solution formed the positive pole. The entire left hand was immersed in a bowl of tap water containing a tinned copper wire as the negative pole. The current varied from experiment to experiment, ranging from 0.5 to $3 \mathrm{~mA}$. The duration also varied, from 20 seconds to 15 minutes. For the majority of subjects $1 \mathrm{~mA}$. was passed for five minutes.

Bretylium tosylate A $1 \%$ solution of bretylium tosylate in distilled water was used. The apparatus was the same as in the atropine experiments and the bretylium ion was likewise introduced into the finger from the positive pole. Preliminary experiments indicated that much larger quantities of electricity would be required to achieve the desired effects than in the case of atropine. When larger quantities were tried, however, small seconddegree burns resulted, which were limited to the dorsum of the finger, especially in the region of the hair follicles. This suggested that most of the current was entering the finger through these low resistance pathways, presumably resulting in an uneven distribution of bretylium within the finger. To overcome these difficulties the following procedure was devised in which the finger was iontophoresed in several stages.

The distal half of the finger was immersed in the bretylium solution and a current of 2 to $2.5 \mathrm{~mA}$. was passed for 15 minutes. This usually caused a tingling sensation and elicited some erythema in the region of the hair follicles. The finger was removed from the solution and dried on a clean towel, and silicone grease, which has a high electrical resistance, was smeared over the vulnerable areas. The finger was replaced in the solution and $2.5 \mathrm{~mA}$. were passed for a further 15 minutes, after which silicone grease was spread over the entire dorsum and lateral aspects of the finger. A current of 2.5 to $3 \mathrm{~mA}$. was then passed for 30 minutes, presumably restricted to the palmar surface. In a final period of iontophoresis only the tip of the finger was placed in the solution, $2.5 \mathrm{~mA}$. being passed for 30 minutes.

Normal saline Iontophoresis with normal saline was used as a control procedure, sodium ions being introduced into the finger from the positive pole. The currents and times corresponded to those used for atropine and bretylium, and in the latter case the same special procedure was employed.

\section{EXPERIMENTAL PROCEDURE}

ATROPINE EXPERIMENTS After the subject had rested on the couch for 10 minutes to acclimatize to the room conditions, the skin resistance in two adjacent fingers of the right hand was recorded for 10 to 15 minutes while a 
few stimuli were applied. Pulse volume recordings were omitted in order to prevent any possibility of the fingers becoming contaminated with silicone grease. Measurement of the psycho-galvanic reflexes as changes in conductance usually revealed some small difference in reactivity in the two fingers. On these occasions the more reactive finger was usually selected for atropinization. The electrodes were removed and the less active finger was iontophoresed with normal saline as a control. The other finger was then iontophoresed with atropine at the same current for the same time. Immediately afterwards the skin resistance in the two fingers and the pulse volume in the atropinized finger were recorded for at least an hour while stimuli were applied in random order. In some experiments recording continued at intervals for periods of 10 minutes in every half hour until the effects attributable to the atropine were no longer apparent.

BRETYLIUM EXPERIMENTS In view of the delayed onset of action of bretylium pre-iontophoresis recordings were considered to be valueless and were omitted. The procedure finally adopted was as follows. The experiment commenced in the late afternoon when bretylium was iontophoresed into a finger of the right hand for a total of 90 minutes in divided periods with intervening rests. Control experiments with normal saline were conducted separately in view of the long period of iontophoresis. The subject returned the following morning when the skin resistance in the treated finger and the pulse volumes in the treated and in an adjacent control finger were simultaneously recorded for 20 to 30 minutes. Stimuli were applied randomly and included two or three applications of the cold pressor test. Finally, skin resistance recordings were taken from the two fingers so that their psycho-galvanic reflexes could be compared. In some cases further recordings were taken on the same evening and again on the following day.

\section{RESULTS}

EFFECTS OF ATROPINE The effects of atropine on the psycho-galvanic reflex are presented collectively in Fig. 1. In the three experiments which were performed first iontophoresis was carried out with quantities of electricity of the order of $3 \mathrm{~mA}$. for 10 minutes ( 1.8 coulombs) since this dose had been used previously by Carmichael et al. (1941) and Montagu (1958). The psycho-galvanic reflex was abolished in the atropinized finger on every occasion, and an example is shown in Fig. 2. A series of experiments was then carried out on one subject to determine the minimum dose required to obtain this result. Simple immersion of a finger in atropine solution for 15 minutes without the passage of a current did not have any detectable effect on either the psychogalvanic reflex or the skin resistance level. Iontophoresis with $0.5 \mathrm{~mA}$. for 30 or 45 seconds $(0.015$ and 0.022 coulomb) caused only a slight transient diminution of the responses in the treated finger. The
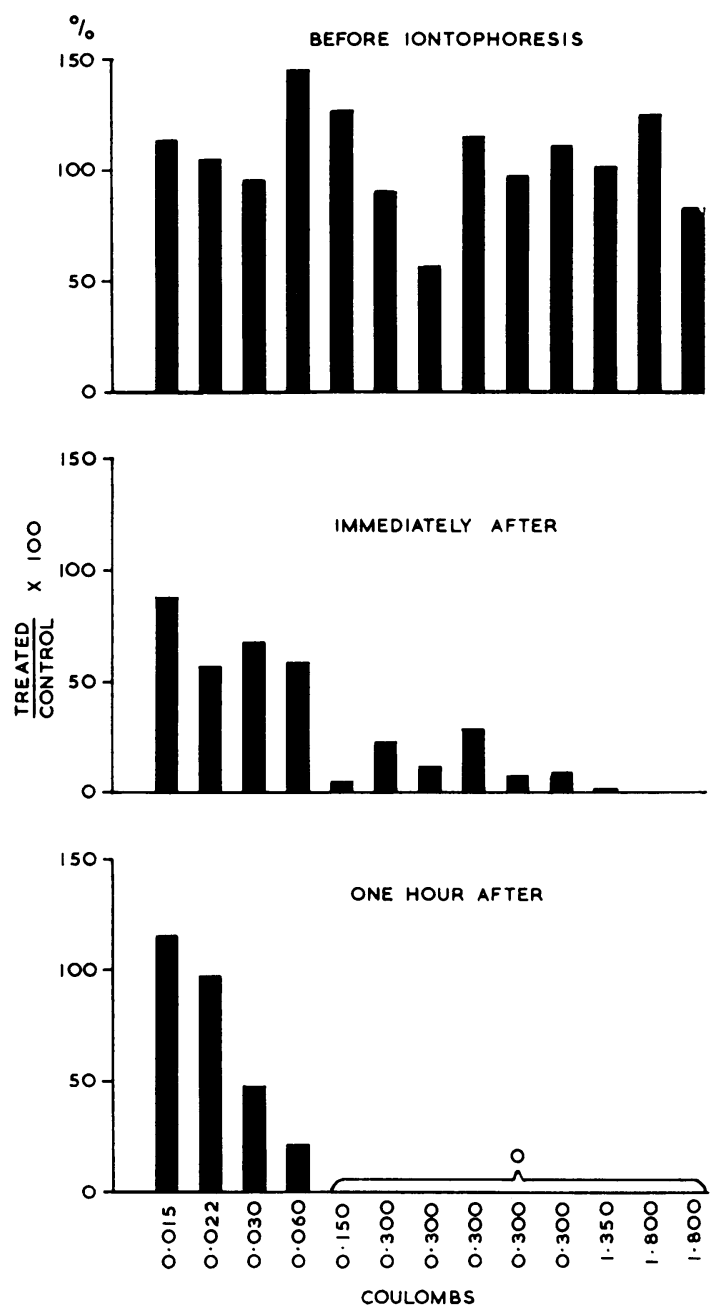

FIG. 1. Effect of atropine on the psycho-galvanic reflex. Each column represents a separate experiment, height of column denoting activity in treated finger expressed as a percentage of corresponding activity in control finger. Activities were measured by summing all psycho-galvanic reflexes in a five-minute period.

same current for one minute $(0.03$ coulomb) had a more pronounced effect, the psycho-galvanic reflex in the treated finger decreasing to about half of that in the control finger. Moreover, some effects were still apparent three hours later. When the time was increased to two minutes at $0.5 \mathrm{~mA}$. (0.06 coulomb), the psycho-galvanic reflex was reduced to one-fifth of the control value one hour after iontophoresis. Finally, iontophoresis for five minutes at $0.5 \mathrm{~mA}$. $(0 \cdot 15$ coulomb) abolished the psycho-galvanic reflex 


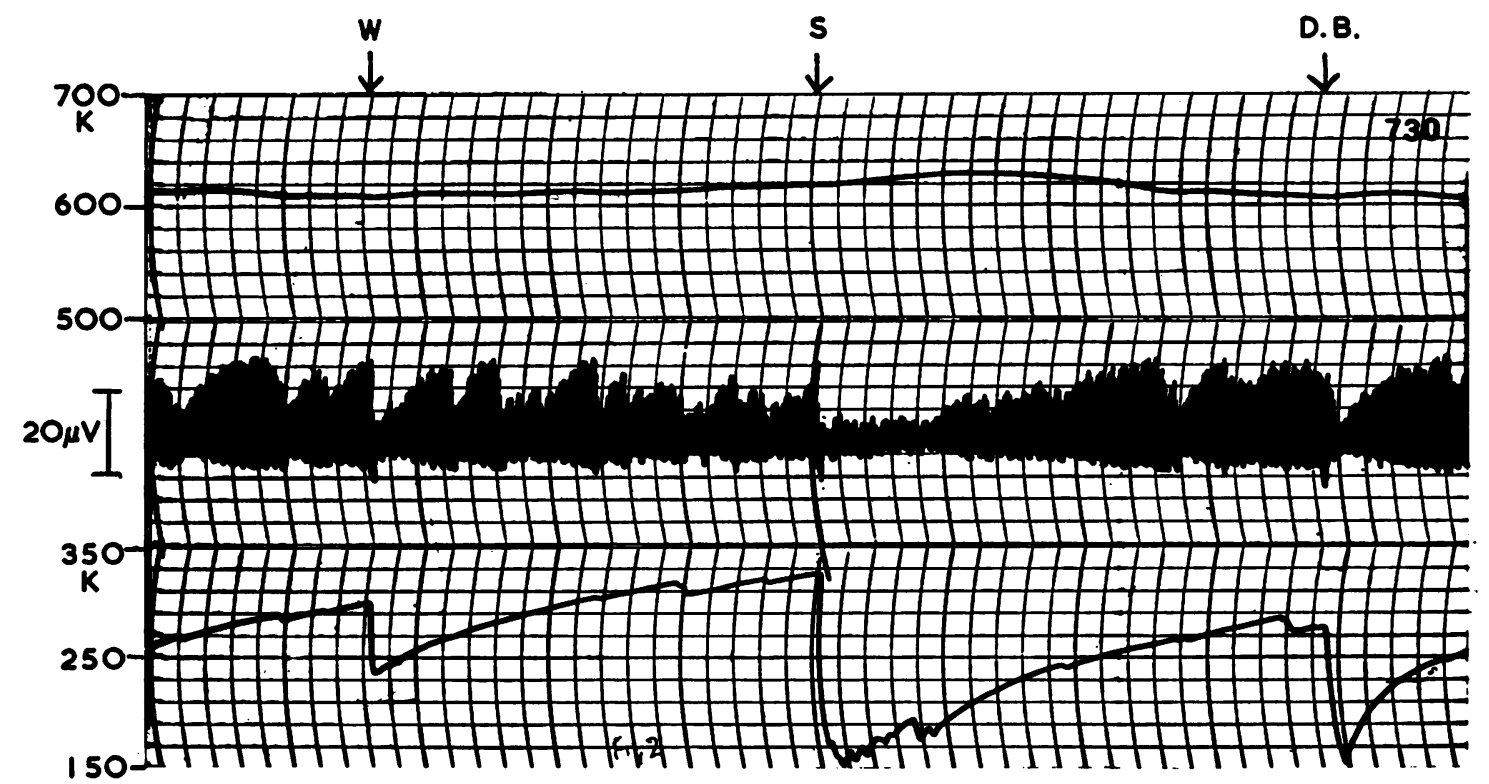

FIG. 2. Responses obtained 60 minutes after iontophoresis with atropine at $1.5 \mathrm{~mA}$. for

15 minutes (1.35 coulombs). Upper trace, skin resistance of atropinized finger; middle trace,

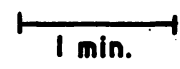

pulse volume of atropinized finger; lower trace, skin resistance of control finger (iontophoresed with saline). Stimuli, $W=$ whistle, $S=$ shot, $D . B .=$ deep breath. Note numerous 'spontaneous' fluctuations in pulse volume trace. Artefact in this trace following shot is attributable to a 'startle reaction'.

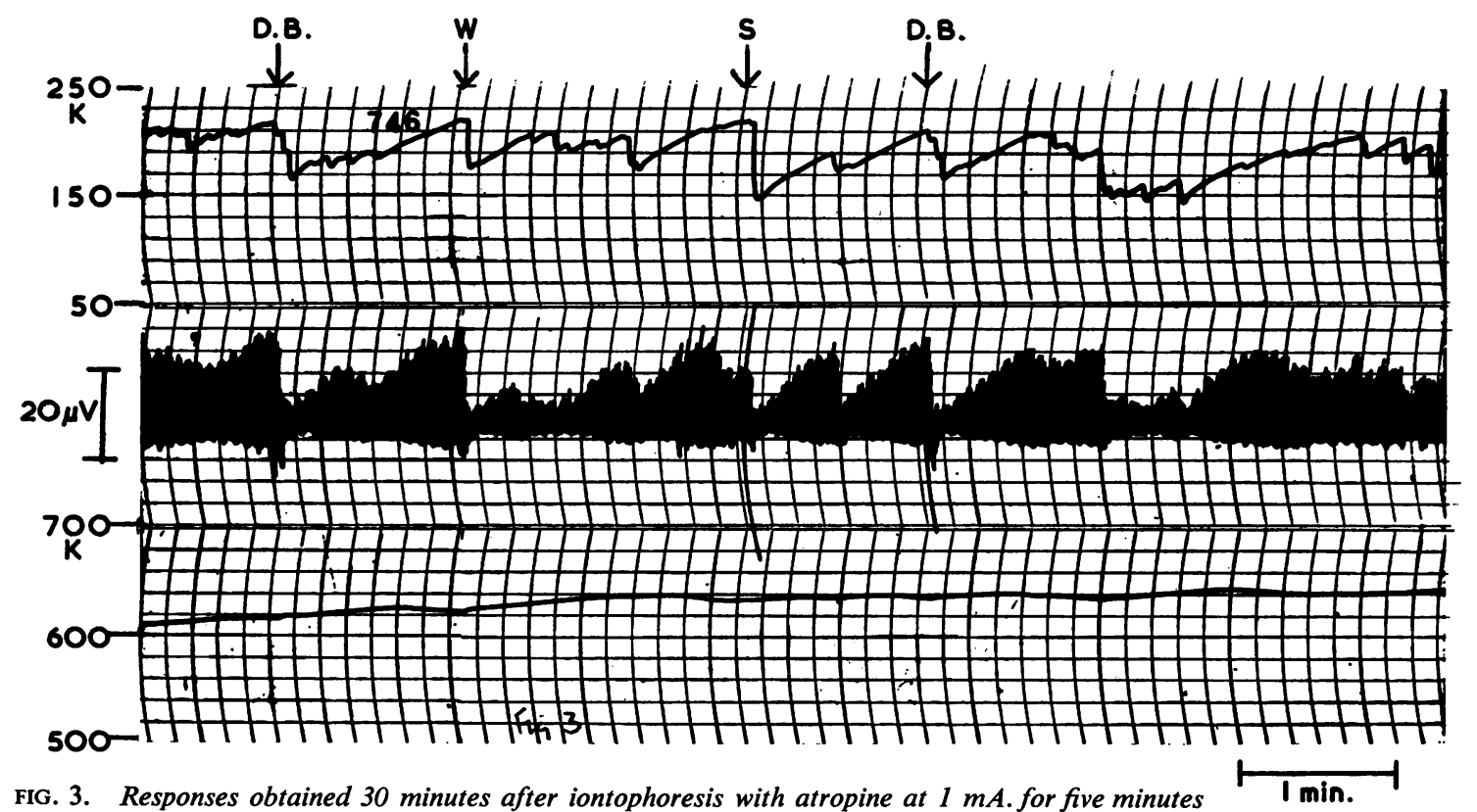

$(0.3$ coulomb $)$. Upper trace, skin resistance of control finger (iontophoresed with saline); middle

trace, pulse volume of atropinized finger; lower trace, skin resistance of atropinized finger. Stimuli, D.B. = deep breath, $W=$ whistle, $S=$ shot. Note similar 'spontaneous' fluctuations in upper and middle traces. 
completely. To ensure that the dosage was adequate, coulomb) was subsequently chosen as the standard procedure and five subjects were so treated. The psycho-galvanic reflex was abolished in each case, as exemplified in Fig. 3. Immediately after iontophoresis a marked diminution of the psychogalvanic reflex was apparent but small responses could still be elicited for a short time. The psychogalvanic reflex was consistently abolished between 30 and 40 minutes after the start of iontophoresis. The full effects persisted for four to six hours before the reappearance of any responses.

Atropinization invariably caused a marked increase in the level of the skin resistance, and the difference between the treated and control fingers can be seen in Figs. 2 and 3. The initial levels before iontophoresis ranged from 25,000 to 250,000 ohms. Immediately after iontophoresis they had increased to between 250,000 and 500,000 ohms and were rising steadily. The maximum recorded resistances ranged from 600,000 to $1,200,000 \mathrm{ohms}$. At this time the treated finger was dry and rough to the touch, and the subjects themselves sometimes commented on this. The resistance always started to drop before the psycho-galvanic reflex reappeared, ultimately approximating to the level in the control finger about five to seven hours after iontophoresis.

In none of the experiments did atropinization appear to have had any effect on the pulse volume. atropinization with $1 \mathrm{~mA}$. for five minutes $(0 \cdot 3$

In every case the pulse volume reacted to stimuli and no changes paralleling the diminution and disappearance of the psycho-galvanic reflex were noted. Marked and sometimes prolonged decreases in pulse volume can be seen in both Figs. 2 and 3.

EFFECTS OF BRETYLIUM About four to six hours after iontophoresis evidence of vasodilatation began to appear in the treated finger, which became red and hot and started to throb. Furthermore, on exposure to cold the finger remained warm and red instead of blanching. These signs persisted for about 24 to 36 hours and then gradually disappeared.

In the earlier experiments effects attributable to the bretylium first appeared in the pulse volume tracing about four to six hours after iontophoresis, i.e., their onset occurred contemporaneously with the appearance of the above clinical signs. In view of this long delay in onset, recordings in subsequent experiments were not taken until these signs were well established.

Some difficulty was encountered in abolishing the pulse volume reactivity completely. Initially, iontophoresis was tried with quantities of electricity of the order of two coulombs, as in the atropine experiments. The effect, however, was slight. Subsequent experiments were conducted with progressively larger doses. A current of 2 to $3 \mathrm{~mA}$. for 30 minutes (approx. 4 to 5 coulombs) was found to reduce the pulse volume responses to about three-quarters of

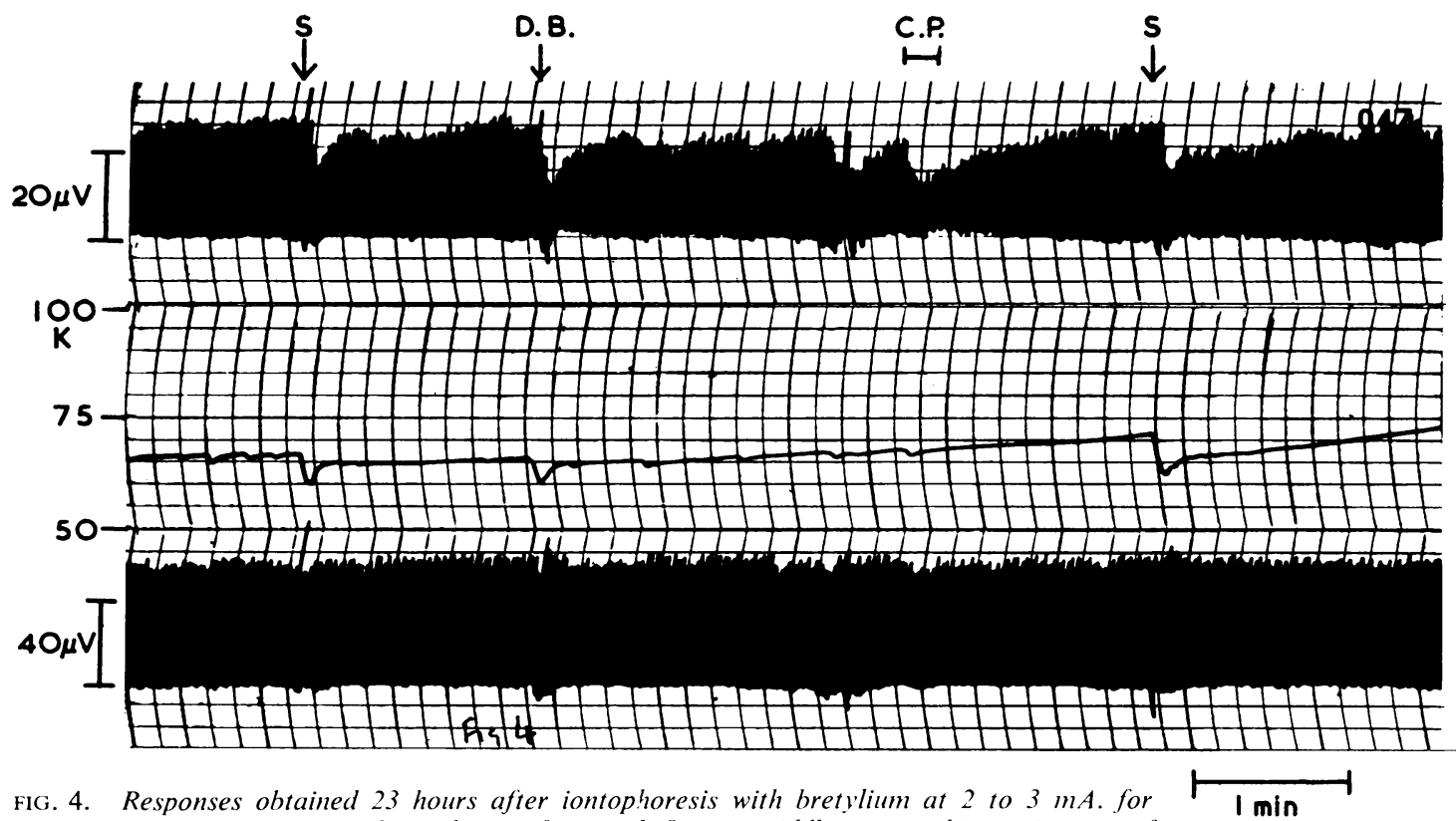

90 minutes. Upper trace, pulse volume of control finger; middle trace, skin resistance of treated finger; lower trace, pulse volume of treated finger. Stimuli, $S-$ shot, D.B. deep breath, C.P. cold pressor test. 


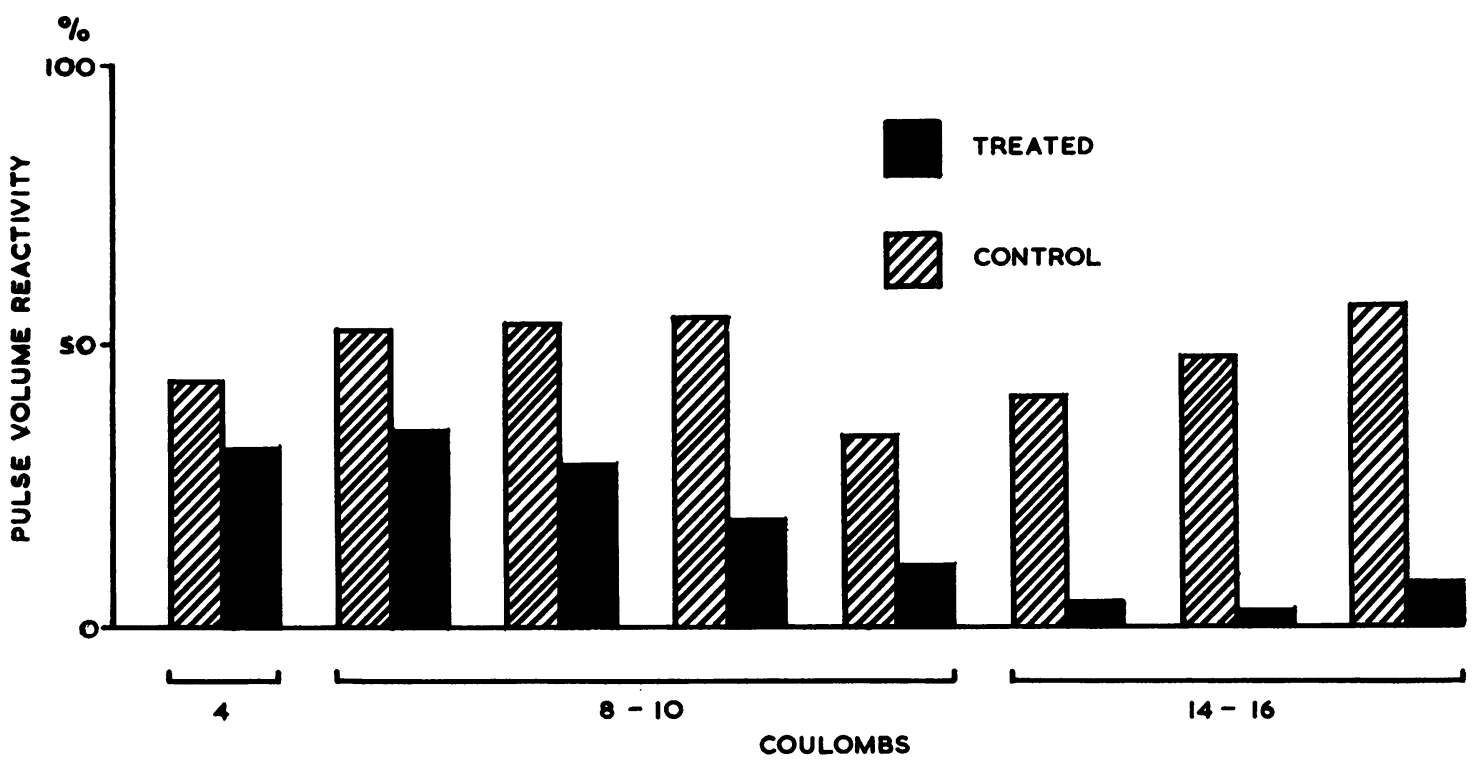

FIG. 5. Effect of bretylium on pulse volume reactivity 18 hours after iontophoresis. Pulse volume reactivity is defined as decrease in pulse volume amplitude following a stimulus expressed as a percentage of pre-stimulus level. The values shown were derived from analysis of five consecutive pairs of responses. Each pair of columns represents a separate experiment.

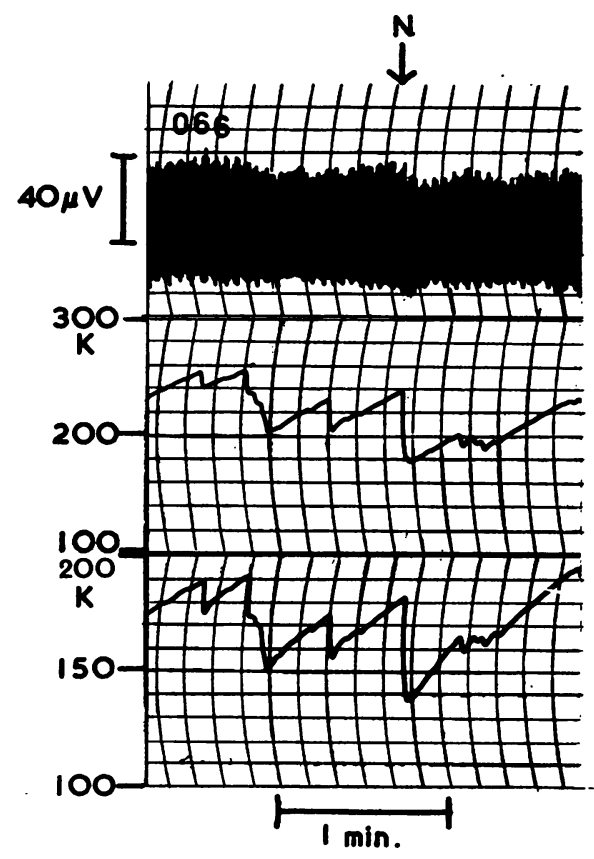

FIG. 6. Responses obtained 24 hours after iontophoresis with bretylium at 2 to $3 \mathrm{~mA}$. for 90 minutes. Upper trace, pulse volume of treated finger; middle trace, skin resistance of treated finger; lower trace, skin resistance of control finger. $N$ denotes an auditory stimulus. the size of those in the control finger. The same current for 60 minutes (approx. 8 to 10 coulombs) reduced the responses to one half of those in the control finger. Finally, three subjects were iontophoresed with 2 to $3 \mathrm{~mA}$. for 90 minutes (approx. 12 to 16 coulombs), resulting in the virtual disappearance of the responses in each case. An example of this is shown in Fig. 4, and the results obtained in all these experiments are presented diagrammatically in Fig. 5.

In the three final experiments recordings of the pulse volume 18 to 24 hours after iontophoresis showed a large constant pulse. The difference in pulse volume amplitude in the treated and control fingers may be seen in Fig. 4, in which the lower trace was recorded at half the sensitivity of the upper channel. In all three subjects reactions to stimuli and to the cold pressor test were scarcely detectable. In two subjects a slight increase in pulse volume was apparent during the inspiratory phase of a deep breath; in the third case a slight decrease was noted. These effects persisted throughout the day after iontophoresis but they were found to be waning on the following morning.

Iontophoresis with bretylium had no apparent effect on either the psycho-galvanic reflex or the skin resistance level. When the treated finger was compared with the control, both the psychogalvanic reflexes and the resistance levels were found to be comparable, as seen in the example shown in 
Fig. 6. The relatively small size of the psychogalvanic reflexes in Fig. 4 compared with those seen in Figs. 2 and 3 is deceptive; they are, in fact, of the same order of magnitude when measured in terms of change in conductance.

EFFECTS OF SALINE When a finger which had been iontophoresed with normal saline was compared with an untreated finger, no consistent differences were noted in any of the measures. Recordings taken immediately after iontophoresis with $1 \mathrm{~mA}$. for five mirutes showed no effects. A current of 2 to $3 \mathrm{~mA}$. for 90 minutes caused transient erythema but recordings taken on the following day appeared quite normal.

\section{DISCUSSION}

The earlier work on the effect of drugs on the psycho-galvanic reflex has been reviewed by Landis and DeWick (1929). Most investigators agreed that atropine causes a rise in skin resistance, but their conclusions concerning its effects on the psychogalvanic reflex were conflicting. The atropine was administered by various routes, viz., orally, intramuscularly and subcutaneously, as well as locally by belladonna plaster or by subcutaneous injection at the site of the electrodes. More recently, iontophoresis has been selected as the method of choice for achieving a high local concentration of the drug. Carmichael et al. (1941) reported that the response was consistently present and showed no signs of diminishing after atropinization by this method. On the other hand, Montagu (1958), using the same technique and dosage, obtained abolition of the psycho-galvanic reflex in three out of four subjects; in the last case, the response was reduced to the point of being scarcely detectable.

The conflicting results of the earlier workers may be attributed, in part, to inadequate atropinization. It appears improbable that cholinergic transmission in the skin could be completely abolished by systemic administration of the drug except in toxic doses. Secondly, atropine injected subcutaneously at the site of the electrodes was doubtless readily absorbed into the system, as evidenced by one investigator's own comments concerning the unpleasant sideeffects experienced by his subjects (Waller, 1919). Another probable explanation for the lack of agreement concerns the method of quantifying the psycho-galvanic reflex and hence of assessing the effects of atropine. Most of the early workers measured the psycho-galvanic reflex as a change in resistance, whereas recent evidence has favoured change in conductance as a more appropriate measure (Woodworth and Schlosberg, 1954). Since conductance is the reciprocal of resistance, a given absolute change in resistance will become progressively smaller when expressed as a change in conductance if the skin resistance level rises. As noted above, a rise in skin resistance after atropine was, in fact, frequently observed by these workers.

Atropinization by iontophoresis appears to afford the best method of obtaining an adequate local concentration of the drug. It seems probable that most of the electric current enters the skin through gland ducts since these constitute low-resistance pathways through the high-resistance stratum corneum. Consequently, the atropine would be preferentially delivered in high concentration at its effector sites in cholinergically innervated sweat glands (Dale and Feldberg, 1934). At the same time, a dose of atropine just sufficient to abolish sudomotor activity would not, in theory, penetrate to deeper structures, such as the blood vessels, in concentrations sufficient to have any appreciable effect. This was considered to be of importance in the present context since atropine in large doses produces vasodilatation of the skin. Nor was any evidence of vasodilatation observed in these experiments.

The abolition of the psycho-galvanic reflex in an atropinized finger and its presence in a control finger after iontophoresis with saline indicates that the observed effect was caused by the drug and not by the electric current. The time course of the effect closely paralleled the known duration of action of atropine, i.e., about four to six hours. A delay in onset of the full effects was noted, abolition of the psycho-galvanic reflex occurring as long as $\mathbf{3 0}$ to $\mathbf{4 0}$ minutes after the beginning of iontophoresis. It seems probable, however, that the minute responses which could still be elicited in the preceding 15 to 20 minutes represented the activity of only a few sweat glands which were the last to be paralysed by the drug.

The pharmacology of bretylium has been extensively studied by Boura and Green (1959). They showed that it causes specific and lasting depression of post-ganglionic, adrenergic, neuro-effector systems, probably by preventing the release of nor-adrenaline at the nerve endings. It does not antagonize circulating catechol amines; indeed, it may even potentiate their effects. It is believed to have little effect on cholinergic nerve endings, and Boura and Green mention specifically that it did not affect the sweating which was induced in a cat's paw by stimulation of the sympathetic chain.

The greater difficulty which was experienced in paralysing adrenergic as opposed to cholinergic transmission may be explained in part on the grounds that bretylium is a less active drug, molecule 
for molecule, than atropine. Therapeutic doses of bretylium are about 100 times greater than clinical doses of atropine. In the present experiments iontophoresis of atropine with 0.15 coulomb was sufficient to abolish the psycho-galvanic reflex; on the other hand, 15 coulombs were required to obtain satisfactory results with bretylium, which has a similar equivalent weight. During iontophoresis bretylium, like atropine, would presumably be introduced into the finger mainly through the low resistance pathways of sweat glands and hair follicles, whence it must diffuse to the more deeply situated blood vessels.

The observed time course of the effects of bretylium followed closely that which was reported by Boura and Green (1959). These workers studied the paralysing effect of a hypodermic injection of bretylium on retraction of the nictitating membrane in intact cats. Weakness was first noticeable three hours after injection and was maximal after 12 to 24 hours. Normal tone was regained 36 to 48 hours after the injection.

The pulse volume tracings after bretylium were distinguished by a marked regularity of pulse volume amplitude. Two factors might have been expected to disturb this regularity. In the first place, the vasomotor effects of any catechol amines released from the adrenal medulla in response to the stimuli would not have been antagonized by the bretylium. Secondly, changes in blood pressure probably occurred in response to the stimuli. The constancy of the pulse volume amplitude which was induced by bretylium indicates that neither of these factors was of any consequence. It seems probable, therefore, that under the conditions of these experiments the pulse volume amplitude was a direct indicator of vasomotor tone. This evidence is in accord with Ackner's (1956) conclusions. In two subjects, an increase in pulse volume amplitude was recorded during the inspiratory phase of a deep breath; in a third case, a decrease occurred. These effects are attributable to the variable changes in venous pressure which are known to occur on deep inspiration.

The present experiments have demonstrated that (1) atropine abolishes the psycho-galvanic reflex without affecting vasomotor activity, and (2) bretylium abolishes vasomotor tone without affecting the psycho-galvanic reflex. It is concluded that the psycho-galvanic reflex occurs independently of vasomotor activity and that it is wholly dependent on a cholinergic mechanism. This supports the theory that the psycho-galvanic reflex is solely attributable to pre-secretory activity in sweat glands.

\section{SUMMARY}

Two series of experiments are reported in which the skin resistance and the pulse volume were simultaneously recorded from the same finger. In one series atropine was introduced into the finger by iontophoresis and the effects on psycho-galvanic reflex and on vasoconstriction were studied. In the second series bretylium was introduced in a similar fashion in order to paralyse adrenergic nerve endings. Iontophoresis with saline was used as a control procedure.

Atropine was found to abolish the psychogalvanic reflex without affecting vasomotor activity. Bretylium abolished vasomotor activity without affecting the psycho-galvanic reflex.

The results confirm the theory that the psychogalvanic reflex is solely dependent on pre-secretory activity in sweat glands.

This work was supported by grant No. MY-3561 from the National Institute of Mental Health of the U.S. Public Health Service.

The authors wish to acknowledge their indebtedness to Professor H. O. Schild for much invaluable advice and encouragement.

Our thanks are also due to Messrs. Burroughs Wellcome for generous supplies of bretylium tosylate.

\section{REFERENCES}

Ackner, B. (1956). J. Psychosom. Res., 1, 3.

Boura, A. L. A., and Green, A. F. (1959). Brit. J. Pharmacol., 14, 536. Carmichael, E. A., Honeyman, W. M., Kolb, L. C., and Stewart, W. K. (1941). J. Physiol. (Lond.), 99, 329.

Dale, H. H., and Feldberg, W. (1934). Ibid., 81, 40P.

Darrow, C. W. (1927). J. exp. Psychol., 10, 197.

Féré, C. (1888). C.R. Soc. Biol. (Paris), 8 ser., 5, 217.

Goadby, K. W., and Goadby, H. K. (1949). J. Physiol. (Lond.), 109, 177.

Landis, C., and DeWick, H. N. (1929). Psychol. Bull., 26, 64.

Lykken, D. T. (1959). J. comp. physiol. Psychol., 52, 629.

McDowall, R. J. S. (1933). Quart. J. exp. Physiol., 23, 277.

Montagu, J. D. (1958). J. Neurol. Neurosurg. Psychiat., 21, 119.

Tarchanoff, J. (1890). Pfügers Arch. ges. Physiol., 46, 46.

Waller, A. D. (1919). Proc. roy. Soc. B., 91, 32.

Woodworth, R. S., and Schlosberg, H. (1954). Experimental Psycho$\log y, 3$ rd ed., p. 140. Methuen, London. 